\title{
Friction Stir Welding of Discontinuously Reinforced Aluminum Matrix Composites: A Review
}

\author{
D. Wang $\cdot$ B. L. Xiao $\cdot$ D. R. Ni $\cdot$ Z. Y. Ma
}

Received: 14 August 2014/Revised: 20 August 2014/Published online: 19 September 2014

(C) The Chinese Society for Metals and Springer-Verlag Berlin Heidelberg 2014

\begin{abstract}
Friction stir welding (FSW) is considered a promising welding technique for joining the aluminum matrix composites (AMCs) to avoid the drawbacks of the fusion welding. High joint efficiencies of $60 \%-100 \%$ could be obtained in the FSW joints of AMCs. However, due to the existence of hard reinforcing particles in the AMCs, the wearing of welding tool during FSW is an unavoidable problem. Moreover, the low ductility of the AMCs limits the welding process window. As the hard materials such as Ferro-Titanit alloy, cermet, and WC/Co were applied to produce the welding tools, the wearing of the tools was significantly reduced and the sound joints could be achieved at high welding speed for the AMCs with low reinforcement volume fraction. In this article, current state of understanding and development of welding tool wearing and FSW parameters of AMCs are viewed. Furthermore, the factors affecting the microstructure and mechanical properties of the joints are evaluated in detail.
\end{abstract}

KEY WORDS: Metal matrix composite; Friction stir welding; Particle, microstructure; Wear

\section{Introduction}

Discontinuously reinforced aluminum matrix composites (AMCs) exhibit improved stiffness, strength, wear resistance, and reduced coefficient of thermal expansion over monolithic matrix alloys and have been applied in the aerospace and automotive industries [1]. Wide industrial applications of the AMCs depend on effective joining methods. However, the weldability of these composites is significantly reduced due to the addition of ceramic reinforcements. Although many welding methods, especially the fusion welding methods have been applied to weld the AMCs, it is hard to achieve defect-free AMCs joints [2,3].

Available online at http://link.springer.com/journal/40195

D. Wang · B. L. Xiao - D. R. Ni · Z. Y. Ma $(\square)$

Shenyang National Laboratory for Materials Science, Institute of

Metal Research, Chinese Academy of Sciences, Shenyang

110016, China

e-mail: zyma@imr.ac.cn
The drawbacks associated with the fusion welding include: (a) the incomplete mixing of the parent and filler materials; (b) the presence of porosity as large as $100 \mu \mathrm{m}$ in the fusion zone; (c) the excess eutectic formation; (d) the formation of undesirable deleterious phases such as $\mathrm{Al}_{4} \mathrm{C}_{3}$. Therefore, a solid-state welding technique is highly desirable for joining AMCs $[4,5]$.

Friction stir welding (FSW) is a novel solid-state joining technique, particularly applied in aerospace and automotive industries [4]. In the welding process, localized heating, resulting from friction between the tool and workpieces, softens the material around the pin, and the combination of tool rotation and translation results in movement of material from the front to the back of the pin, thereby producing a welded joint in solid state. Therefore, FSW is considered a promising welding technique for joining the AMCs to avoid the drawbacks of the fusion welding.

In the last decade, a number of investigations [5-11] have been conducted to join the AMCs by FSW. High joint efficiencies of $60 \%-100 \%$ could be obtained in the FSW joints of AMCs. However, due to the existence of 
Table 1 Tool wearing of friction stir welded aluminum matrix composites

\begin{tabular}{|c|c|c|c|c|c|}
\hline Materials & $\begin{array}{l}\text { Rotation rate } \\
(\mathrm{r} / \mathrm{min})\end{array}$ & $\begin{array}{l}\text { Welding speed } \\
(\mathrm{mm} / \mathrm{min})\end{array}$ & Tool material & $\begin{array}{l}\text { Wearing of } \\
\text { tool }\end{array}$ & $\begin{array}{l}\text { Welding distance } \\
(\mathrm{mm})\end{array}$ \\
\hline 15 vol\% B4Cp/6061Al [15] & 670 & 114 & H13 tool steel & Serious & 254 \\
\hline $20 \mathrm{vol} \% \mathrm{Al} 2 \mathrm{O} 3 \mathrm{p} / 6061 \mathrm{Al}[16]$ & $500-2,000$ & 60 & Standard tool steel & Serious & 310 \\
\hline 15 vol\% SiCp/2009Al [17] & 600 & 50 & H13 tool steel & Serious & - \\
\hline 20 vol\% SiCp/A359 [18] & 1,000 & $180-540$ & Standard tool steel & Serious & 610 \\
\hline 15 vol\% SiCp/A356 [19] & 1,200 & 30 & D2 tool steel & - & 60 \\
\hline 25 vol\% $\mathrm{SiCp} / 2,009 \mathrm{Al}[20]$ & 800 & 120 & TiAlN-coated HSS-steel & - & - \\
\hline $10 \mathrm{vol} \% \mathrm{Al} 2 \mathrm{O} 3 \mathrm{p} / 7005 \mathrm{Al}[12]$ & 600 & 300 & Ferro-Titanit alloy & - & - \\
\hline 30 vol\% SiCp/AC4A Al [21] & $1,500-2,000$ & $25-150$ & WC-Co hard alloy & Normal & 240 \\
\hline 30 vol\% SiCp/A359 [14] & 1,000 & 76 & WC-Co hard alloy & Normal & 1320 \\
\hline
\end{tabular}
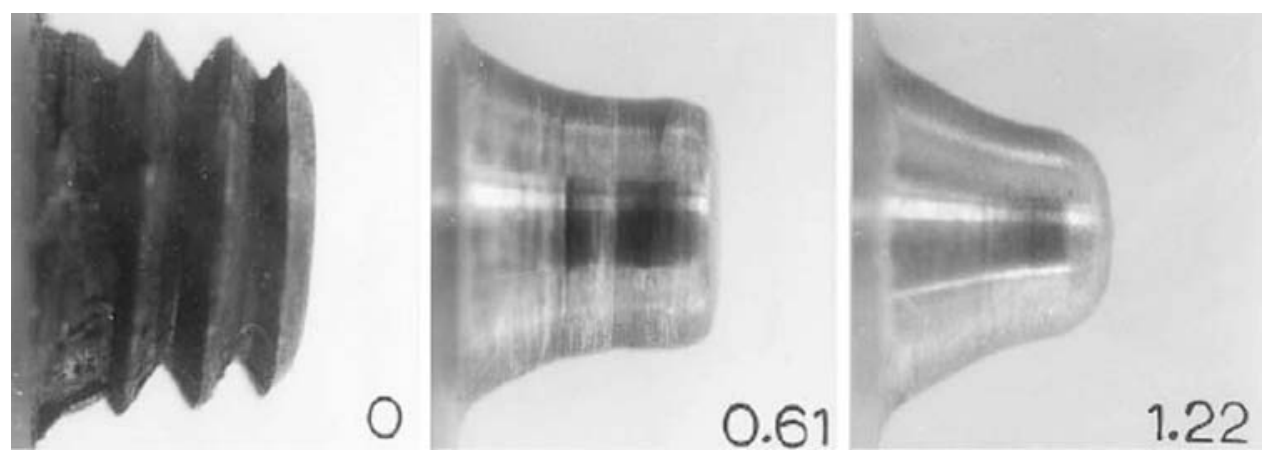

Fig. 1 Tool wear features for $20 \mathrm{vol} \% \mathrm{Al}_{2} \mathrm{O}_{3} \mathrm{p} / 6061 \mathrm{Al}$ joint using $\mathrm{O} 1$ tool steel tools [22]

reinforcing particles in the AMCs, it is not very easy to achieve a sound joints of the AMCs compared to that of the monolithic Al alloys. Some important problems, such as tool wearing and narrow welding process window, must be faced. These factors would affect the microstructure and mechanical properties of the joints. Therefore, the development of the FSW for AMCs was slow in the early stage.

Recently, as some hard materials were applied to produce the welding tools for the AMCs [12-14], the tool wearing was effectively inhibited. Furthermore, the sound joints could be achieved at a wide welding process window. Especially, the high welding speed could be applied for the heat treatable AMCs with low reinforcement volume fraction [13]. This indicates that FSW is a promising joining technique for the manufacture of the AMC components.

In this article, current state of understanding of FSW for the AMCs are viewed, with main focus on the welding tool wear, FSW parameters, microstructure, and mechanical properties of joints.

\section{Welding Tool Wear}

A critical problem associated with FSW of the AMCs is severe wearing of the welding tool due to the presence of hard ceramic reinforcements. Table 1 summarizes the reported tool wearing during FSW for various AMCs. It is clear that the welding tools made from tool steel exhibited serious wearing in the welding process of the AMCs, as shown in Fig. 1.

Nelson et al. [15] observed that for the threaded tool made from $\mathrm{H} 13$ tool steel, heat-treated to $R_{\mathrm{c}}>52$, when welding $15 \mathrm{vol} \% \mathrm{~B}_{4} \mathrm{Cp} / 6061 \mathrm{Al}$ at a tool rotation rate of $670 \mathrm{r} / \mathrm{min}$ and a traverse speed of $114 \mathrm{~mm} / \mathrm{min}$, no threads were left on the pin and the shoulder was worn out by approximately $2 \mathrm{~mm}$ in less than $254 \mathrm{~mm}$ of weld. SEM backscattered images revealed that the wear debris from the tool was deposited through the thickness of the $\mathrm{B}_{4} \mathrm{Cp} /$ $6061 \mathrm{Al}$ weld and on the surface of the weld in particular. It was suggested that the wear debris would affect the quality of the weld and reduce the properties.

Later, Prado et al. [16] investigated the tool wear behavior in $\mathrm{FSW}$ of $20 \mathrm{vol} \% \mathrm{Al}_{2} \mathrm{O}_{3} \mathrm{p} / 6061 \mathrm{Al}$ composite. For $\mathrm{O} 1$ tool steel threaded pin, heat-treated to an $R_{\mathrm{c}}$ hardness of 62 , at tool rotation rates of $500-2,000 \mathrm{r} / \mathrm{min}$ and a traverse speed of $60 \mathrm{~mm} / \mathrm{min}$, while no apparent tool wear was noted for FSW of 6061Al, severe tool wear occurred for FSW of $\mathrm{Al}_{2} \mathrm{O}_{3} \mathrm{p} / 6061 \mathrm{Al}$ composite. The wear rate of the tool increases linearly with increasing linear welding distance. The largest wear rate was observed at a 


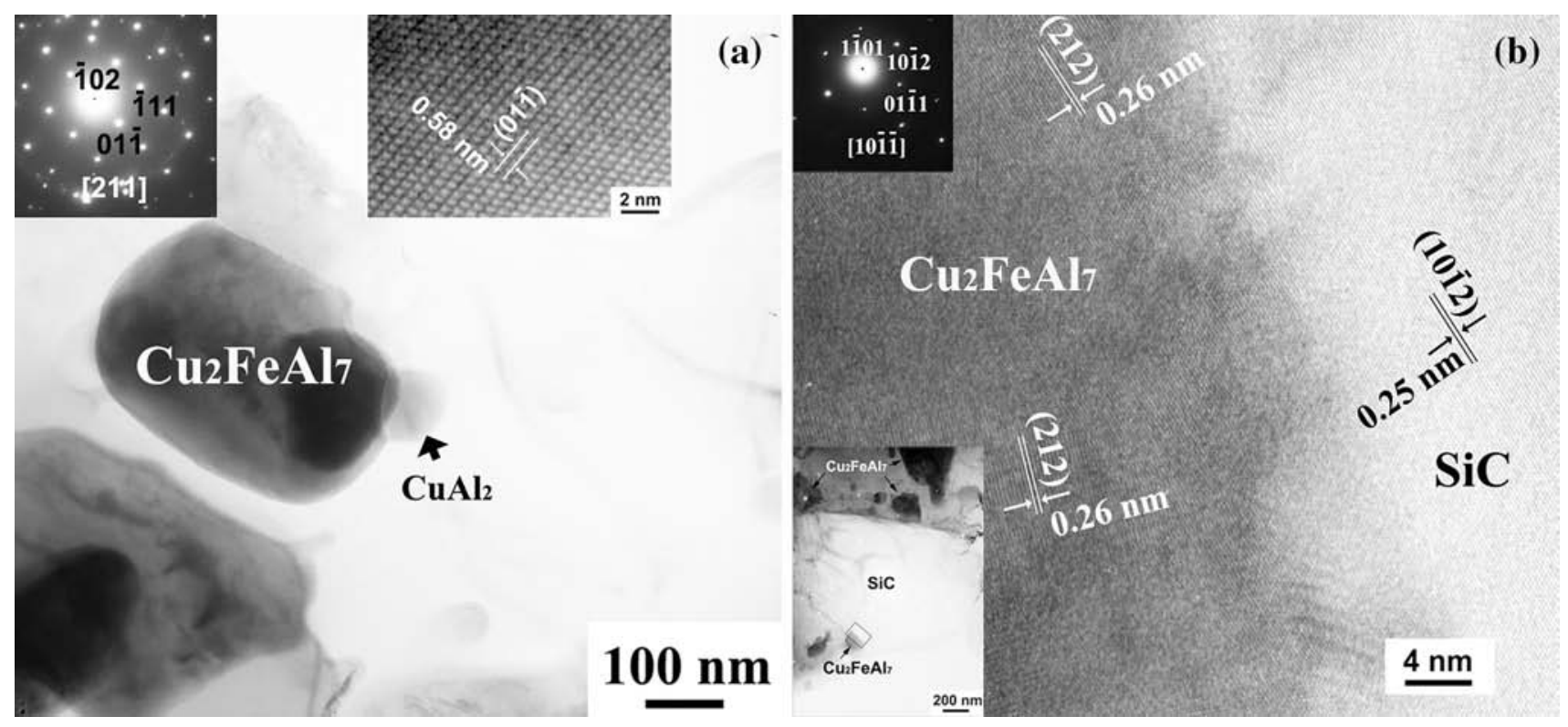

Fig. 2 TEM image of NZ of 15 vol\% SiC/2009Al joint with inserts showing a selected-area diffraction pattern and an HREM image of $\mathrm{Cu}_{2} \mathrm{FeAl}_{7}$ phase [17]

tool rotation rate of $1,000 \mathrm{r} / \mathrm{min}$. This means that the wear rate of tool did not increase when the tool rotation rate was increased above $1,000 \mathrm{r} / \mathrm{min}$. A possible reason for this is the improvement of flow properties of the composite at high tool rotation rate due to increased thermal input.

Recently, Feng et al. [17] reported that the $\mathrm{Fe}$ worn by the hard and sharp $\mathrm{SiC}$ particles formed the $\mathrm{Cu}_{2} \mathrm{FeAl}_{7}$ phase abound the $\mathrm{SiC}$ particles, when $\mathrm{SiCp} / 2009 \mathrm{Al}$ was FSWed by a steel tool. Two types of the $\mathrm{Cu}_{2} \mathrm{FeAl}_{7}$ were identified in the nugget zone (NZ), i.e., the single-crystal $\mathrm{Cu}_{2} \mathrm{FeAl}_{7}$ phase around the $\mathrm{SiC}$ particles and the polycrystalline nanostructured $\mathrm{Cu}_{2} \mathrm{FeAl}_{7}$ phase on the interface of the $\mathrm{SiC}$ particles with a specifically crystallographic orientation relationship (1012) $)_{\mathrm{SiC}} \|(212)_{\mathrm{Cu} F \mathrm{FeAl7}}$, as shown in Fig. 2 [17]. The $\mathrm{Cu}_{2} \mathrm{FeAl}_{7}$ particle formed at the interface of the $\mathrm{SiC}$ particle might reduce the interfacial bonding between $\mathrm{SiC}$ and aluminum matrix. Furthermore, the formation of $\mathrm{Cu}_{2} \mathrm{FeAl}_{7}$ phase reduced the amount of the precipitates in the matrix due to the dilution of $\mathrm{Cu}$. Both of these two factors decreased the mechanical properties of the FSW composite joints [17].

To reduce the tool wearing, some hard materials were applied to produce the welding tools (Table 1). Ceschini et al. [12] used the Ferro-Titanit alloy to weld the 10 vol\% $\mathrm{Al}_{2} \mathrm{O}_{3} \mathrm{p} / 7 \mathrm{~A} 10 \mathrm{Al}$. The strength of the joints was $81 \%$ of the base material (BM). However, the wearing of the tools was not reported. Wang et al. [13] used the cermet tool to weld the $17 \mathrm{vol} \% \mathrm{SiCp} / 2009 \mathrm{Al}$. At a high welding speed of $800 \mathrm{~mm} / \mathrm{min}$, the strength of the joint was almost equivalent to that of the BM. The tools were not noticeably worn in the welding process.
However, for the AMCs with high reinforcement volume fraction, the wearing could not be completely avoided even using the cermet tools. Prater et al. [14] compared the wearing of $\mathrm{O} 1$ steel tools and $\mathrm{WC} / \mathrm{Co}$ tools under welding 30 vol\% SiCp/A359 composite. Although the wearing resistance of the WC/Co tools was obviously superior to that of the $\mathrm{O} 1$ steel tools, the wearing of the WC/Co tools occurred, with the loss of the volume being about $4.23 \%$ after welding for $1,320 \mathrm{~mm}$. Moreover, Liu et al. [21] used the WC-Co hard alloy tools to weld $30 \mathrm{vol} \% \mathrm{SiCp} / \mathrm{AC} 4 \mathrm{~A}$ composite at tool rotation rates of 1,500-2,000 r/min and traverse speeds of $25-150 \mathrm{~mm} / \mathrm{min}$. The wearing rate of the tool increased with decreasing the welding speed. The maximum wear rate was always produced in the initial welding process. For example, after welding $240 \mathrm{~mm}$, the pin diameter decreased by $11 \%$. After welding $1,800 \mathrm{~mm}$, the pin diameter decreased by $27 \%$ at the maximum-wear location.

Prado et al. [22] and Shindo et al. [18] found that the tool wearing in the $\mathrm{FSW}$ process of $\mathrm{Al}_{2} \mathrm{O}_{3} \mathrm{p} / 6061 \mathrm{Al}$ and $\mathrm{SiCp} / 359 \mathrm{Al}$ composites produced a self-optimized shape, which resulted in sound welds and no additional tool wear when the self-optimization was achieved. This indicates that the geometry of welding tools exerted important effect on the material flow and tool wearing. This provides a constructive clue for the geometry design of the welding tool.

In summary, when the steel tools were used to weld the ceramic particles reinforced $\mathrm{Al}$ matrix composites, severe tool wearing occurred. This inhibited long-distance welding of the composites. Moreover, the wearing debris would 
decrease the mechanical properties of the joints. For the composites with particle volume fraction of less than $30 \%$, the cermet tool could work well without severe wearing. The tool geometry design is very important for reducing tool wearing and improving the material flow.

\section{FSW Parameters}

The nature of FSW is a severe plastic deformation process. Due to the presence of hard ceramic reinforcements, the AMCs exhibit lower ductility than the monolithic alloys even at high temperatures. Therefore, it is considered that sound FSW joints of the AMCs were hard to achieve under welding parameters with low heat input. Furthermore, as the reinforcement volume fraction increased, the flow ability of the AMCs was further reduced [5, 15, 19]. Therefore, higher heat input welding parameters should be applied.

Figure 3 shows the typical cross-sectional macrograph of FSW 15 vol\% SiCp/2009Al joints welded at a traverse speed of $50 \mathrm{~mm} / \mathrm{min}$ and various rotation rates by the cylindrically shaped threaded pin. It is clear that at a low heat input welding parameters $(400 \mathrm{r} / \mathrm{min}$ rotation rate), some defects were observed in the bottom of the NZ. This was attributed to insufficient material flow. As the heat input increased, sound FSW joint was achieved (Fig. 3b) [23].

For the AMCs with low reinforcement volume fraction, for example, the $10 \mathrm{vol} \% \mathrm{Al}_{2} \mathrm{O}_{3} / 7005 \mathrm{Al}$ composite [12], the sound joint could be achieved at a relative low heat input welding parameters $(600 \mathrm{r} / \mathrm{min}$ rotation rate and $300 \mathrm{~mm} / \mathrm{min}$ welding speed). However, for the $30 \mathrm{vol} \%$ $\mathrm{SiCp} / \mathrm{AC} 4 \mathrm{~A}$ composite, which was the highest reinforcement volume fraction about the FSW of the AMCs in the existing reports, much higher heat input welding parameters $(2,000 \mathrm{r} / \mathrm{min}$ rotation rate and $25-150 \mathrm{~mm} / \mathrm{min}$ welding speed) were used to achieve sound joints [21].

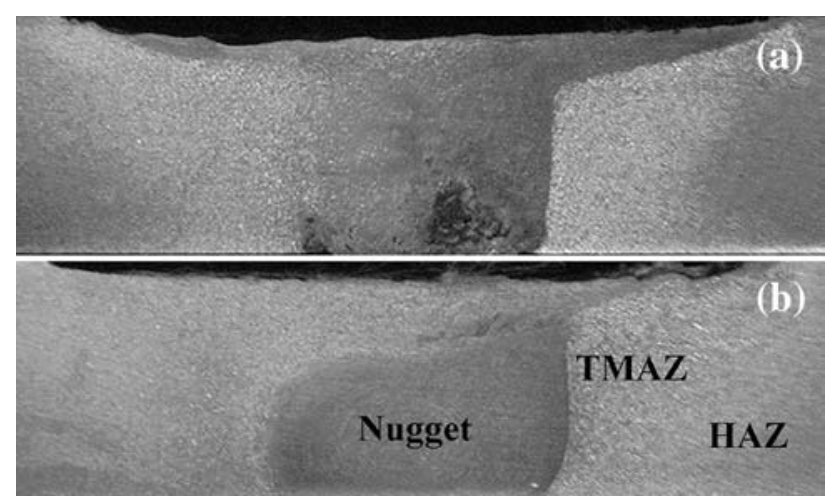

Fig. 3 Typical macrograph of 15 vol\% $\mathrm{SiCp} / 2009 \mathrm{Al}$ joints welded at a traverse speed of $50 \mathrm{~mm} / \mathrm{min}$ and various rotation rates: a $400 \mathrm{r} /$ $\min ; \mathbf{b} 600 \mathrm{r} / \mathrm{min}[23]$
Similar to the heat treatable monolithic alloys, the size and distribution of the precipitates in the AMCs was sensitive to the temperature. Therefore, the strength of the joints was controlled by the welding parameters. In general, the strength of the joints was reduced under the high heat input welding parameters [6]. Therefore, it was important to decrease the heat input of the FSW process to achieve the high strength joints of the AMCs.

The suitable shape of the welding tools was beneficial to promoting the material flow during the welding process, and therefore decreased the heat input of welding process [24]. Vijay and Murugan [25] conducted FSW of $10 \mathrm{wt} \%$ $\mathrm{TiB}_{2} / \mathrm{Al}$ using the simple-shaped pin such as square, hexagon, and octagon with both straight and tapered configurations. It was reported that the joint prepared using the square tool exhibited better tensile strength compared to other tools.

According to the experience with monolithic $\mathrm{Al}$ alloys, the threaded pin or more complex-shaped pins could improve the material flow during the FSW process [26, 27]. However, for the AMCs, there were no detailed experiments in this subject due to the severe wearing of the welding tools. The limited researches suggested that if the tools were made by ultra-hard material, the joints of AMCs could be achieved under low heat input welding parameters. For example, Marzoli et al. [28] reported that the $20 \mathrm{vol} \% \mathrm{Al}_{2} \mathrm{O}_{3} / 6061 \mathrm{Al}$ composite could be welded at a rotation rate of $600 \mathrm{r} / \mathrm{min}$ and a welding speed of $300 \mathrm{~mm} /$ min using the ultra-hard tool. Similarly, Wang et al. [13] reported that the sound joints of $17 \mathrm{vol} \% \mathrm{SiC} / 2009 \mathrm{Al}$ could be achieved at $1,000 \mathrm{r} / \mathrm{min}$ and $800 \mathrm{~mm} / \mathrm{min}$ using the threaded cermet tool. The strength of the joint was similar to that of the BM.

In summary, the welding parameter windows of the AMCs were affected by both the reinforcement volume fraction of the AMCs and the welding tools significantly. For the AMCs with high reinforcement volume fraction, the high heat input welding parameters were required due to poor flow ability of the AMCs. However, for the AMCs with low reinforcement volume fraction, the sound joints could be achieved under low heat input (high welding speed) when using the welding tools made by hard materials with complex shape (such as threaded pin).

\section{Microstructure of FSW AMCs Joints}

\subsection{Macrostructure of Nugget Zone}

Similar to monolithic Al alloys, the FSW AMCs joints consisted of three zones: NZ, thermomechanically affected zone (TMAZ), and heat affected zone (HAZ). As shown in Fig. $3 b$, the NZ exhibited an elliptical shape and onion 
rings were distinctly visible. Although the shape of the NZ was different for various tool shapes and FSW parameters, some similar macrostructure features were observed in various FSW composite joints. For example, the onion rings were generally observed in the NZ.

Marzoli et al. [28] reported that the onion rings were mainly visible on the retreating side of the NZ in FSW $20 \mathrm{vol} \%$ $\mathrm{Al}_{2} \mathrm{O}_{3} \mathrm{p} / 6061 \mathrm{Al}$ joint and it was considered that the material flow of the aluminum matrix was partially hindered by the alumina particles, and the recrystallization of the matrix was not complete in this case. Uzun [20] and Storjohann et al. [2] found that in the NZ of FSW 25 vol\% SiCp/2124Al and $20 \mathrm{vol} \% \mathrm{Al}_{2} \mathrm{O}_{3} \mathrm{p} / 6061 \mathrm{Al}$ joints the onion rings consisted of the alternating bands of high and low density of fine reinforcing particles. However, for the FSW 15 vol\% SiCp/2009Al [6], the onion rings consisted of fine $\mathrm{Al}-\mathrm{Cu}-\mathrm{Fe}-\mathrm{Mg}$ and $\mathrm{Al}-\mathrm{Cu}-\mathrm{Fe}$ phase particle-rich bands, and the $\mathrm{SiC}$ particles did not segregate in the onion rings. This was attributed to that the strain rate gradient was not high enough to drive the large $\mathrm{SiC}$ particles to segregate to the high density bands of particles.

\subsection{Reinforcing Particle Distribution in Nugget Zone}

For the BM, the reinforcing particle clusters were often observed $[13,18]$. After the FSW, the particle distribution in the NZ was improved significantly. The particle clusters were broken up and the particle distribution became homogeneous due to the intense plastic deformation and material mixing in the NZ. Furthermore, the size of the particles decreased in the NZ and the edges and corners of the particles were obviously blunted due to the cracking of some large particles and knocking off of sharp corners and edges from the large particles resulting from the stirring breaking effect of the tools.

Figure 4 shows typical microstructure of the particle distribution in the NZ and $\mathrm{BM}$ of the $15 \mathrm{vol} \% \mathrm{SiCp} / 2009 \mathrm{Al}$ composite. It is apparent that after FSW, the sharp edges and corners of some particles became blunt in the NZ, due to the abrasion during welding. Figure 5 shows the results of quantitative measurements of the particle size distribution in the BM and the NZ of the FSW sample. For the FSW sample, the size of the SiC particles in the NZ was approximately the average value of the BM in the two directions. Furthermore, the fraction of $\mathrm{SiC}$ particles larger than $8.5 \mu \mathrm{m}$ was higher than that of the BM along the transverse direction. This implies that part of the SiC

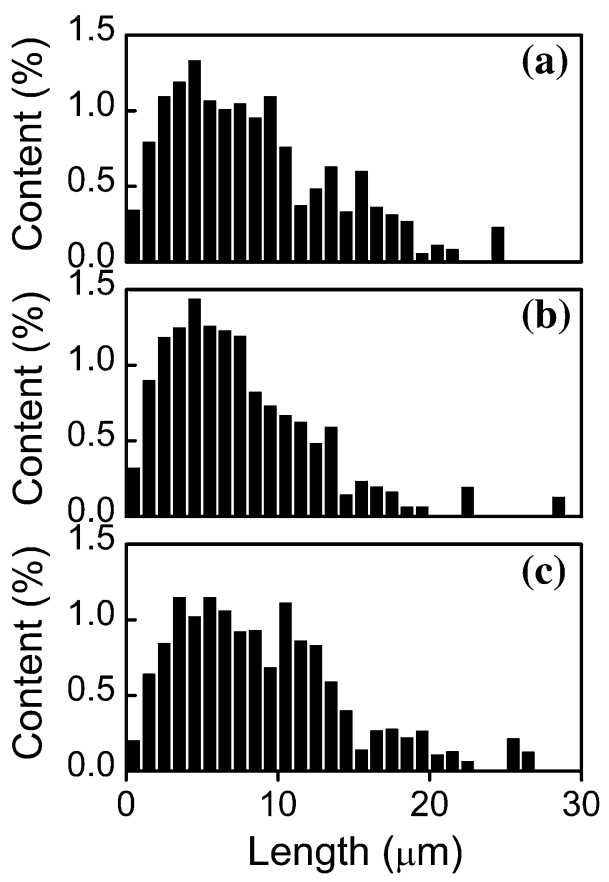

Fig. 5 Quantitative measurements of particle size distribution in $15 \mathrm{vol} \% \mathrm{SiCp} / 2009 \mathrm{Al}$ joint and $\mathrm{BM}$ : a as-FSW sample; b BM perpendicular to the rolling direction; $\mathbf{c} \mathrm{BM}$ along the rolling direction [28]
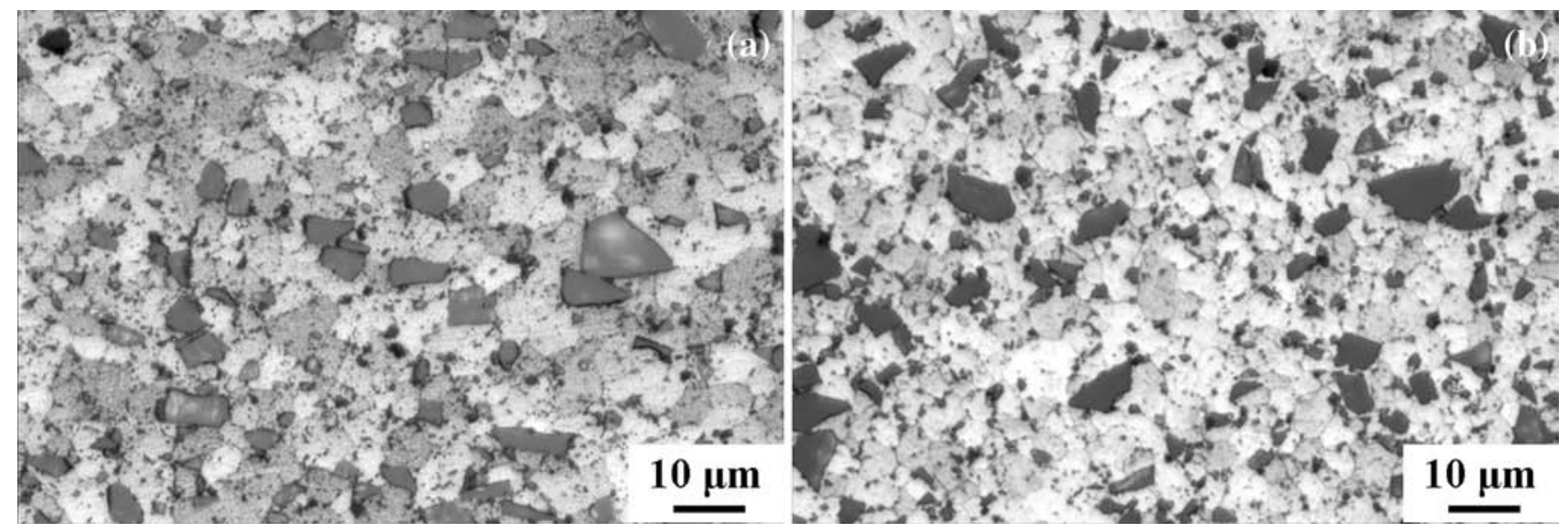

Fig. 4 Typical microstructure showing particle distribution of 15 vol\% SiCp/2009Al joints: a BM; b NZ [28] 
particles flowed and rotated in the matrix with the stirring of the welding tool and some large $\mathrm{SiC}$ particles were broken up during FSW. Similar phenomena were observed in the FSW joints of other AMCs such as $25 \mathrm{vol} \% \mathrm{SiCp} /$ $2124 \mathrm{Al}$ and $20 \mathrm{vol} \% \mathrm{Al}_{2} \mathrm{O}_{3} \mathrm{p} / 6061 \mathrm{Al}[20,28]$.

\subsection{Recrystallization in Nugget Zone}

Similar to the monolithic Al alloys, the NZ of the FSW AMC joints was also characterized by the fine equiaxed recrystallized grains, as shown in Fig. 4. This suggests that dynamic recrystallization (DRX) occurred in the NZ of the FSW AMC joints. It is believed that the reinforcement particles had a large effect on the recrystallization behavior [29]. The reinforcing particles increased local strain in the matrix. Therefore, the DRX nucleated in regions of very high dislocation density between the reinforcements [30].

Furthermore, the cracked reinforcing particles also affected the recrystallization behavior. For the FSW joint of $15 \mathrm{vol} \% \mathrm{SiCp} / 2009 \mathrm{Al}$ composite, new surfaces of the fractured $\mathrm{SiC}$ particles directly contacted with the $\mathrm{Al}$ matrix with high deformation energy in the NZ. In this case, the Al matrix was prone to nucleating on the $\mathrm{SiC}$ particles and forming nano-scaled grains to reduce the free energy of the interfaces [31]. In addition, the reinforcing particles would inhibit the growth of the recrystallized grains. Feng et al. [6] reported that the FSW 15 vol\% SiCp/ 2009Al composite exhibited a grain size of $\sim 5 \mu \mathrm{m}$ in the $\mathrm{NZ}$, which was significantly refined compared to that of the BM. After a post-T4 treatment, the grain size of the NZ increased to $\sim 8 \mu \mathrm{m}$, indicating that the fine grains in the composites were relatively stable. By comparison, abnormal grain growth was often observed in the FSW aluminum alloys [32].

\subsection{Evolution of Precipitates in the Joints}

There were few reports about the evolution of precipitates in the FSW AMC joints. Feng et al. [5] reported that for extruded 15 vol\% $\mathrm{SiCp} / 2009 \mathrm{Al}$ plate, the coarse $\theta\left(\mathrm{Al}_{2} \mathrm{Cu}\right)$ phase particles disappeared in the NZ after FSW and some fine $\theta^{\prime \prime}$ phase particles were observed. This indicates that FSW resulted in the dissolution of the coarse $\theta$ phase particles, which is the equilibrium phase for the 2009Al alloys, and subsequent natural aging led to the precipitation of the fine $\theta^{\prime \prime}$ phase particles.

Wang et al. [13] examined the precipitates in the FSW joints of $17 \mathrm{vol} \% \mathrm{SiCp} / 2009 \mathrm{Al}-\mathrm{T} 4$ sheet produced at a high welding speed of $800 \mathrm{~mm} / \mathrm{min}$, as shown in Fig. 6. In the $\mathrm{BM}$, the strengthening resulted mainly from the clusters of the solute atoms. Small-sized $\mathrm{Al}_{2} \mathrm{Cu}(\sim 100 \mathrm{~nm})$ and $\mathrm{Al}_{2} \mathrm{CuMg}(\sim 20 \mathrm{~nm})$ phases were present in the NZ due to the short thermal cycle of the FSW process. In the HAZ, the high welding speed resulted in a much-shortened length of thermal exposure during FSW. In this case, only part of the clusters dissolved into the $\mathrm{Al}$ matrix.

In summary, the microstructure of the FSW AMC joints was different from the monolithic $\mathrm{Al}$ alloys due to the existence of reinforcing particles. After FSW, the size of the reinforcing particles decreased in the NZ due to the cracking of some large particles. The particle clusters were broken up and the particle distribution became homogeneous due to the intense plastic deformation and material mixing in the NZ. The reinforcing particles promoted the DRX and controlled the grain size of the NZ. The limited investigations indicated that the evolution of the precipitates in the FSW AMC joints was similar to that in the monolithic Al alloys. The high welding speed could decrease the size of the precipitates in the joints.

\section{Mechanical Properties of FSW AMC Joints}

\subsection{Hardness of the Joints}

Similar to that for the monolithic Al alloys, the hardness profile of the joints for the heat treatable AMCs was influenced by the heat input [13]. Figure 7 shows typical hardness profiles of FSW 17 vol\% SiCp/2009Al-T4 joints at various welding speeds. At lower welding speeds of 50
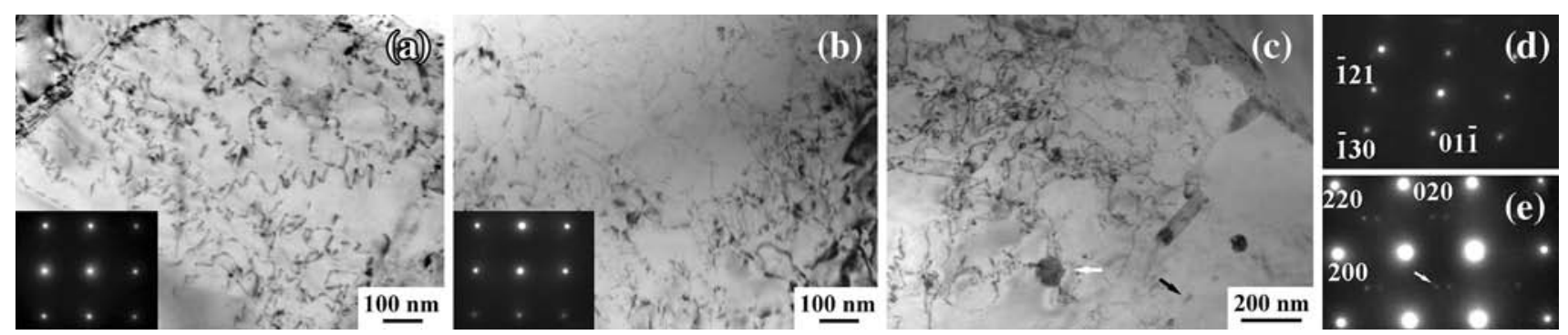

Fig. 6 TEM micrographs and SAED patterns of $17 \mathrm{vol} \% \mathrm{SiCp} / 2009 \mathrm{Al}$ joint at $800 \mathrm{~mm} / \mathrm{min}$ : a BM; b low-hardness zone of HAZ; c nugget zone; $\mathbf{d}$ SAED pattern of $\mathrm{Al}_{2} \mathrm{Cu}$ phase, region marked by white arrow in $\mathbf{c} ; \mathbf{e} \mathrm{SAED}$ pattern of the $\mathrm{Al}$ matrix $\langle 100\rangle$ projection, region marked by black arrow in c [13] 


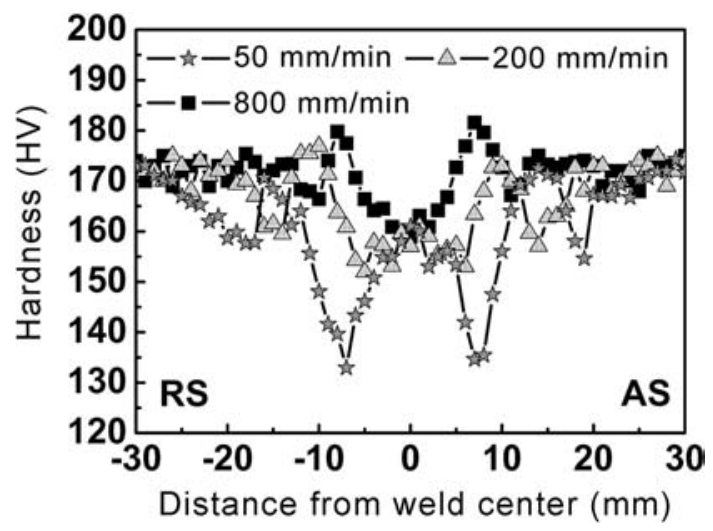

Fig. 7 Hardness profiles of 17 vol\% $\mathrm{SiCp} / 2009 \mathrm{Al}$ joints at various welding speeds of 50,20 , and $800 \mathrm{~mm} / \mathrm{min}$ [13]

and $200 \mathrm{~mm} / \mathrm{min}$, two low-hardness zones were observed in the HAZ on both advancing and retreating sides, similar to those observed in $\mathrm{Al}-\mathrm{Cu}-\mathrm{Mg}$ alloys at lower welding speeds [33]. The first low-hardness zone adjacent to the NZ had the lowest hardness. The HAZ exhibited the lowest hardness due to the coarsening and/or dissolution of the strengthening precipitates, whereas the hardness of the NZ was lower than that of the BM due to the fundamental dissolution of the precipitates. At a higher welding speed of $800 \mathrm{~mm} / \mathrm{min}$, the NZ exhibited the lowest hardness and each HAZ contained only one low-hardness zone, similar to that of the monolithic alloys welded at higher welding speeds [34]. The short thermal cycle of the FSW process resulted in this phenomena, as stated in Sect. 4.4.

\subsection{Tensile Properties of the Joints}

Table 2 summarizes the reported results of transverse tensile properties of the FSW AMC joints. The ultimate tensile strength (UTS) of the joints could reach up to $62 \%$ $100 \%$ of the BMs. The joint efficiencies were significantly higher than those achieved by other welding methods [3, 4]. For the cast AMCs, the high joint efficiencies were easy to achieve due to the low strength of the BM. For the wrought AMCs, the joint efficiencies were relatively lower than that of the cast AMCs.

There were several factors affecting the tensile properties of the FSW composite joints. Ceschini et al. [12] produced the $\mathrm{FSW} 10$ vol\% $\mathrm{Al}_{2} \mathrm{O}_{3} \mathrm{p} / 7075 \mathrm{Al}$ joint at a high welding speed of $300 \mathrm{~mm} / \mathrm{min}$ and obtained a joint efficiency of $82 \%$, which was attributed to the welding defect in the NZ due to the high welding speed. If the welding defects could be avoided, the AMC joints generally failed in the HAZ with the lowest hardness due to the coarsening and/or dissolution of the precipitates. For example, Marzoli et al. [27] reported that for the FSW 20 vol\% $\mathrm{Al}_{2} \mathrm{O}_{3} \mathrm{p} /$ $6061 \mathrm{Al}$ joints prepared using ultra-hardness material tool, no tool wear and welding defects were observed in the NZ, and the UTS of the joints was $70 \%$ of the BM with the joints failing in the HAZ. Similarly, Wang et al. [13] reported that for the FSW joints of $17 \mathrm{vol} \% \mathrm{SiCp} / 2009 \mathrm{Al}$ sheets welded using the ultra-hardness cermet tools with threads, at a high welding speed of $800 \mathrm{~mm} / \mathrm{min}$, the strength of the joint was almost equal to that of the BM.

Table 2 Tensile properties of friction stir welded aluminum matrix composites

\begin{tabular}{|c|c|c|c|c|c|c|c|c|}
\hline Materials & $\begin{array}{l}\text { Plate thickness } \\
(\mathrm{mm})\end{array}$ & $\begin{array}{l}\text { Rotation rate } \\
(\mathrm{r} / \mathrm{min})\end{array}$ & $\begin{array}{l}\text { Welding speed } \\
(\mathrm{mm} / \mathrm{min})\end{array}$ & BM condition & $\begin{array}{l}\text { YS } \\
(\mathrm{MPa})\end{array}$ & $\begin{array}{l}\text { UTS } \\
\text { (MPa) }\end{array}$ & $\mathrm{El}(\%)$ & $\begin{array}{l}\text { Joint eff. } \\
(\%)\end{array}$ \\
\hline $22 \mathrm{vol} \% \mathrm{Al}_{2} \mathrm{O}_{3} \mathrm{p} / 6061[35]$ & 4 & 880 & 260 & Cast & - & 217 & - & 99 \\
\hline 10 vol\% $\mathrm{TiB}_{2} / \mathrm{Al}[25]$ & 6 & 2,000 & 30 & Cast & - & $223-282$ & $3.4-6.7$ & 79-99 \\
\hline 15 vol\% $\mathrm{Mg}_{2} \mathrm{Si} / \mathrm{Al}[36]$ & 6 & 1,120 & 125 & Cast & - & 115 & - & 100 \\
\hline $10 \mathrm{wt} \% \mathrm{ZrB}_{2} / 6061$ [37] & 6 & 1,150 & 50 & Cast & - & 240 & 1 & 95 \\
\hline 20 wt\% AlNp/6061 [38] & 6 & 1,200 & 55 & Cast & - & 225 & - & 93 \\
\hline 10 vol\% $\mathrm{SiCp} / 6061$ [39] & 6 & 1,100 & 45 & Cast & 126 & 206 & 6.8 & 74 \\
\hline $10 \mathrm{vol} \% \mathrm{Al}_{2} \mathrm{O}_{3} \mathrm{p} / 7005$ [12] & 7 & 600 & 300 & Extruded $+\mathrm{T} 6$ & 263 & 299 & 1.2 & 82 \\
\hline $10 \mathrm{vol} \% \mathrm{Al}_{2} \mathrm{O}_{3} \mathrm{p} / 7005[40]$ & 7 & 800 & 56 & T6 & 245 & 260 & 0.58 & 84 \\
\hline $20 \mathrm{vol} \% \mathrm{Al}_{2} \mathrm{O}_{3} \mathrm{p} / 6061[40]$ & 7 & 800 & 56 & T6 & 280 & 329 & 1.3 & 87 \\
\hline $20 \mathrm{vol} \% \mathrm{Al}_{2} \mathrm{O}_{3 \mathrm{p}} / 6061[28]$ & 7 & - & & Extruded $+\mathrm{T} 6$ & 234 & 251 & - & 70 \\
\hline $20 \mathrm{vol} \% \mathrm{Al}_{2} \mathrm{O}_{3} \mathrm{p} / 6061$ & 7 & - & & Extruded $+\mathrm{T} 6$ & 193 & 262 & 2.8 & 72 \\
\hline 6 vol\% $\mathrm{B}_{4} \mathrm{C} / 6063$ [42] & 4.5 & 1,500 & 600 & Extruded $+\mathrm{T} 5$ & 125 & 172 & 2.5 & 62 \\
\hline 10.5 vol\% $\mathrm{B}_{4} \mathrm{C} / 6063$ [42] & 4.5 & 1,500 & 600 & Extruded $+\mathrm{T} 5$ & 125 & 176 & 2.5 & 62 \\
\hline 25 vol\% $\mathrm{SiCp} / 2124$ [43] & 15 & 550 & 75 & Forged $+\mathrm{T} 6$ & 407 & 552 & 2.6 & 74.4 \\
\hline 17 vol\% SiCp/2009 [44] & 3 & 1,000 & 50 & Rolled + T351 & 278 & 443 & 4.7 & 77 \\
\hline 17 vol\% $\mathrm{SiCp} / 2009$ [13] & 3 & 1,000 & 800 & Rolled $+\mathrm{T} 4$ & 341 & 501 & 3.5 & 97 \\
\hline
\end{tabular}

Joint eff. $=\mathrm{UTS}_{\text {joint }} / \mathrm{UTS}_{\mathrm{BM}}$ 


\subsection{Fatigue Properties of the Joints}

For the AMCs, there were only a few investigations about the fatigue properties of the FSW joints. In an investigation on the low-cycle fatigue of FSW $10 \mathrm{vol} \% \mathrm{Al}_{2} \mathrm{O}_{3} \mathrm{p} / 7005 \mathrm{Al}$ joint [12], it was observed that the reinforcing particles were significantly broken up in the FSW process and distributed homogenously in the NZ. In this case, the local stress was not high enough to crack the particles, and less cracked particles were observed on the failure surface compared to the BM. However, the welding defect, due to high welding speed $(300 \mathrm{~mm} / \mathrm{min})$, decreased the fatigue life of the joints and the fatigue life of all the FSW joints was lower than that of the BM.

$\mathrm{Ni}$ et al. [45] reported the high cycle fatigue behavior of FSW 17 vol\% SiCp/2009Al joint without welding defects. At higher stress amplitudes, fatigue fracture occurred in the HAZ and the FSW joint showed a shorter fatigue life than that of BM. However, at lower stress amplitudes, fatigue fracture tended to move toward the NZ due to the high residual stresses generated during the FSW process. The fatigue life was equivalent to that of BM. Furthermore, Pirondi et al. [7, 46] reported that the fine dynamically recrystallized grains in the NZ accelerated fatigue crack propagation. However, the fragmented particles, which generated during the FSW process, resulted in the crack deflection and then inhibited the fatigue crack growth.

In summary, for the FSW AMC joints without welding defects, the hardness distribution and the joint efficiency of the joints were similar to those of the monolithic $\mathrm{Al}$ alloys. Especially for the heat treatable AMCs, the tensile properties of the joints could be increased significantly by increasing the welding speed. However, for the fatigue properties, fine dynamically recrystallized grains and the fragmented particles in the NZ affected the fatigue crack growth, while the high residual stresses in the joints resulted in the fatigue fracture location moving toward the $\mathrm{NZ}$ at lower stress amplitudes.

\section{Summary and Future Outlook}

The solid-state nature of the FSW could avoid the defects of fusion welding such as porosity, inhomogeneous distribution of reinforcements, and the formation of undesirable deleterious phases. The sound joints with high mechanical properties could be achieved by FSW. However, the tool wearing and narrow welding windows are two main challenges for FSW of the AMCs. As the hard materials, such as Ferro-Titanit alloy, cermet, and $\mathrm{WC} / \mathrm{Co}$, are applied to produce the welding tools, the sound joints of AMCs with low reinforcement volume fraction could be easily achieved. However, for the AMCs with high reinforcement volume fraction, it is still very important to seek more wearable tool materials with sufficient hardness and toughness at the welding temperature. Furthermore, much attention should be paid to the tool geometry design to improve the material flow to increase the welding window. In addition to the tensile properties of the AMCs joints, the corrosion resistance, fatigue properties and so on, which are important for the industrial applications, should be investigated. Although some challenges still exist, FSW offers very attractive possibilities for successful commercial applications of AMCs.

Acknowledgments This work was financially supported by the National Basic Research Program of China (No. 2012CB619600)

\section{References}

[1] S.C. Tjong, Z.Y. Ma, Mater. Sci. Eng. R 29, 49 (2000)

[2] D. Storjohann, O.M. Barabash, S.S. Babu, S.A. David, P.S. Sklad, E.E. Bloom, Metall. Mater. Trans. A 36, 3237 (2005)

[3] X.H. Wang, J.T. Niu, S.K. Guan, L.J. Wang, D.F. Cheng, Mater. Sci. Eng. A 499, 106 (2009)

[4] J. Guo, P. Gougeon, F. Nadeau, X.G. Chen, Can. Metall. Q. 51, 277 (2012)

[5] R.S. Mishra, Z.Y. Ma, Mater. Sci. Eng. R 50, 1 (2005)

[6] A.H. Feng, B.L. Xiao, Z.Y. Ma, Compos. Sci. Technol. 68, 2141 (2008)

[7] A. Pirondi, L. Collini, Int. J. Fatigue 31, 111 (2009)

[8] F. Khodabakhshi, H.G. Yazdabadi, A.H. Kokabi, A. Simchi, Mater. Sci. Eng. A 585, 222 (2013)

[9] D. Wang, Q.Z. Wang, B.L. Xiao, D.R. Ni, Z.Y. Ma, Acta Metall. Sin. 50, 489 (2014). (in Chinese)

[10] D. Wang, B.L. Xiao, Q.Z. Wang, Z.Y. Ma, Mater. Des. 47, 243 (2013)

[11] D.R. Ni, D.L. Chen, D. Wang, B.L. Xiao, Z.Y. Ma, Mater. Des. 51, 199 (2013)

[12] L. Ceschini, I. Boromei, G. Minak, A. Morri, F. Tarterini, Compos. Sci. Technol. 67, 605 (2007)

[13] D. Wang, Q.Z. Wang, B.L. Xiao, Z.Y. Ma, Mater. Sci. Eng. A 589, 271 (2014)

[14] T. Prater, A. Strauss, G. Cook, B. Gibson, C. Cox, J. Mater. Eng. Perform. 22, 1807 (2013)

[15] T.W. Nelson, H. Zhang, T. Haynes, in Proceedings of the Second Symposium on Friction Stir Welding, Gothenburg, Sweden, June 2000

[16] R.A. Prado, L.E. Murr, D.J. Shindo, K.F. Sota, Scr. Mater. 45, 75 (2001)

[17] A.H. Feng, Z.Y. Ma, Scr. Mater. 57, 1113 (2007)

[18] D.J. Shindo, A.R. Rivera, L.E. Murr, J. Mater. Sci. 37, 4999 (2002)

[19] M. Amirizad, A.H. Kokabi, M.A. Gharacheh, R. Sarrafi, B. Shalchi, M. Azizieh, Mater. Lett. 60, 565 (2006)

[20] H. Uzun, Mater. Des. 28, 1440 (2007)

[21] H.J. Liu, J.C. Feng, H. Fujiib, K. Nogi, Int. J. Mach. Tool Manu. 45, 1635 (2005)

[22] R.A. Prado, L.E. Murr, K.F. Soto, J.C. McClure, Mater. Sci. Eng. A 349, 156 (2003)

[23] Z.Y. Ma, A.H. Feng, B.L. Xiao, J.Z. Fan, L.K. Shi, Mater. Sci. Forum 539-543, 3814 (2007)

[24] Y.N. Zhang, X. Cao, S. Larose, P. Wanjara, Can. Metall. Quart. 51, 250 (2012) 
[25] S.J. Vijay, N. Murugan, Mater. Des. 31, 3585 (2010)

[26] P.A. Colegrove, H.R. Shercliff, Sci. Technol. Weld. Join. 9, 345 (2004)

[27] W.M. Thomas, E.D. Nicholas, J.C. Needham, P. Temple-Smith, S.W.K.W. Kallee, C.J. Dawes, Friction stir welding, UK Patent, No. 2306366, (1996)

[28] L.M. Marzoli, A.V. Strombeck, J.F. Dos Santos, C. Gambaro, L.M. Volpone, Compos. Sci. Technol. 66, 363 (2006)

[29] B. Inem, Mater. Sci. Eng., A 197, 91 (1995)

[30] X.X. Xia, H.J. Mcqueen, Appl. Compos. Mater. 4, 333 (1997)

[31] D. Wang, Q.Z. Wang, B.L. Xiao, Z.Y. Ma, J. Mater. Sci. Technol. 30, 54 (2014)

[32] Y.S. Sato, H. Kokawa, Metall. Mater. Trans. A 32, 3023 (2001)

[33] Z. Zhang, B.L. Xiao, Z.Y. Ma, Acta Mater. 73, 227 (2014)

[34] R.D. Fu, J.F. Zhang, Y.J. Li, J. Kang, H.J. Liu, F.C. Zhang, Mater. Sci. Eng. A 559, 319 (2013)

[35] G. Minak, L. Ceschini, I. Boromei, M. Ponte, Int. J. Fatigue 32, 218 (2010)

[36] H. Nami, H. Adgi, M. Sharifitabar, H. Shamabadi, Mater. Des. 32, 976 (2011)
[37] I. Dinaharana, N. Murugan, Mater. Sci. Eng. A 543, 257 (2012)

[38] N. Murugan, B. Ashok Kumar, Mater. Des. 51, 998 (2013)

[39] P. Periyasamy, B. Mohan, V. Balasubramanian, J. Mater. Eng. Perform. 21, 2417 (2012)

[40] P. Cavaliere, E. Cerri, L. Marzoli, J.D. Santos, Appl. Compos. Mater. 2, 247 (2004)

[41] L. Ceschini, I. Boromei, G. Minak, A. Morri, F. Tarterini, Compos. Part A 38, 1200 (2007)

[42] X.G. Chen, M. da Silva, P. Gougeon, L. St-Georges, Mater. Sci. Eng. A 518, 174 (2009)

[43] F. Cioffi, R. Fernandez, D. Gesto, P. Rey, D. Verdera, G. Gonzalez-Doncel, Compos. Part A 54, 117 (2013)

[44] D.R. Ni, D.L. Chen, D. Wang, B.L. Xiao, Z.Y. Ma, Mater. Sci. Eng. A 608, 1 (2014)

[45] D.R. Ni, D.L. Chen, B.L. Xiao, D. Wang, Z.Y. Ma, Int. J. Fatigue 5, 64 (2013)

[46] A. Pirondi, L. Collini, D. Fersini, Eng. Fract. Mech. 75, 4333 (2008) 